\title{
Suspicious Minds: Apportioning and Avoiding Blame for Distrustful Relationships and Deferring Medical Treatment in South Africa
}

\author{
John Eyles ${ }^{*}$, Bronwyn Harris ${ }^{1}$, Jana Fried ${ }^{2}$, Veloshnee Govender ${ }^{3}$, Loveday Penn-Kekana ${ }^{4}$ \\ ${ }^{1}$ Centre for Health Policy and MRC Research Unit, School of Public Health, Faculty of Health Sciences, \\ University of the Witwatersand, Johannesburg, South Africa \\ ${ }^{2}$ University Research Centre for Agroecology, Water, and Resilience, Coventry University, Coventry, UK \\ ${ }^{3}$ Health Economics Unit, School of Public Health and Family Medicine, University of Cape Town, Cape Town, \\ South Africa \\ ${ }^{4}$ Department of Global Health and Development, Faculty of Epidemiology and Population Health, London \\ School of Hygiene and Tropical Medicine, London, UK \\ Email: ${ }^{*}$ john.eyles@wits.ac.za
}

Received 11 May 2015; accepted 17 July 2015; published 20 July 2015

Copyright (C) 2015 by authors and Scientific Research Publishing Inc.

This work is licensed under the Creative Commons Attribution International License (CC BY). http://creativecommons.org/licenses/by/4.0/

(c) (7) Open Access

\section{Abstract}

This paper examines elements of mistrust, blame and suspicion among patients and providers in the South African health system which affect practice and policy development. Using stories told by patients and providers in Cape Town, Johannesburg and Bushbuckridge, it examines how suspicion is constructed and how others are blamed for adverse outcomes. This paper sets a conceptual framework which examines the attribution of blame in contemporary social and political life, the narratives of 45 patients receiving HIV/AIDS, TB or maternal delivery services and those of 63 providers dealing with similar treatments and arranged across a series of facilities, clinics, hospitals and mobile vans were constructed and shared with participants. These narratives form the basis of the results sections which examines suspicions among both providers and patients with the former seeing the latter as having no respect and regard and providing poor care and access to grants. Providers saw themselves as highly stressed but diligent with service challenges being blamed on patient ignorance, unreasonable demands and failure to follow medical advice. The paper ends with a discussion on how to limit mistrust and reduce suspicion through more co-operative provider-patient relations and what this kind of evidence means for decisionmakers.

\footnotetext{
${ }^{*}$ Corresponding author.
}

How to cite this paper: Eyles, J., Harris, B., Fried, J., Govender, V., \& Penn-Kekana, L. (2015). Suspicious Minds: Apportioning and Avoiding Blame for Distrustful Relationships and Deferring Medical Treatment in South Africa. Sociology Mind, 5, 188-199. http://dx.doi.org/10.4236/sm.2015.53017 


\section{Keywords}

\section{Experiencing Illness, Providing Care, South Africa, Social Phenomenology}

\section{Introduction}

Some twenty years after the dismantling of the Apartheid state, South Africa remains a deeply divided society. Tremendous gains have been made with respect to reconciliation, human rights legislation and the distribution of scarce resources, such as those of health care. South Africa exemplifies a country that has undergone a difficult health transition with remaining issues of infectious diseases, high maternal and child mortality, and the rise of non-communicable diseases. These issues are influenced by the country's colonial and apartheid past and exacerbated by recent demographic and economic changes. The adoption of neoliberal economic policies has resulted in modest economic growth, though high unemployment and growing income inequality persists. Yet basic services have been expanded, and about a quarter of the population now receives social and welfare benefits and grants. Decision-makers need evidence and understanding of the challenges of meeting these goals. In fact, the South African constitution entrenches the rights of access to health care with no one to be denied emergency treatment. But despite some positive developments, health problems and social inequalities rooted in poverty persist (Coovadia et al., 2009). These positive developments must not be overlooked: nor must the South African system's reengineering and reengagement through primary health reform, the development of national health insurance and the commitment to address inequities in health care.

South Africa has similar socio-economic and health issues as many other middle-income countries with great inequalities between rich and poor. But it remains a corporatist state. The corporatist debate in and about South Africa emerged in the mid-1990s and has not really gone away (Desai \& Habib, 1997; Louwrens, 1996). Corporatism is a system of interest representation based on non-competing groups officially sanctioned and subsidized by the state. Channels of influence are not open equally to all, and individuals outside those channels may be denied representation, influence or resources, while those within can gain great advantage through preferential, sometimes corrupt practices. The conundrum in South Africa is that the post-apartheid constitution provides rights to all for equitable treatment. It is the purpose of this paper to examine this relationship between the rights enshrined by citizenship and the practices and proscriptions shaped by the corporatist state. In some ways, the ideal democratic state has been subverted by a rational state with its offices, hierarchies and strict rule enforcement within which some actors and institutions are favoured more than others (Olsen, 2009). We present a microcosm of these relationships as the poor deal with scant health care provision. We bring their voices to policymakers in the commonly understood ideas of awareness of citizen needs and citizen involvement in their health care decisions. This is especially the case as social and political context in South Africa may well reduce trust and make some suspicious of others who seem to benefit greatly. We explore these issues from the perspective of "explanations" of why things are as they are. Who is to blame? Of whom are individuals suspicious? Why are different groups mistrusted? Do these issues damage reform? There is certainly evidence from other marginalized populations which suggests that past experiences of being mistrusted and being accustomed to being mistrusted can result in suspicions of unfair treatment (Ní Raghallaigh, 2013). The paper thus establishes the framework of blame, mistrust and suspicion before discussing setting, methods and analytical framework of narrative. After presenting the findings, their implications are examined for theory and policy-making and practice.

Trust is a vital component in all social interactions, specifically caring ones as between health care provider and patient (Rowe \& Calnan, 2006; Gilson, Pamer, \& Schneider, 2005). But in post-apartheid South Africa there exists a dualism between the rights of democracy and the customary practice of corporatism. For many 20 years of democracy have changed little so there exists mistrust on the part of the populations on the intentions and practices of political and bureaucratic elites. Their behaviour is seen as self-serving and not only are there suspicions of intentions but apportioning blame for poorly serviced health care. Blame (the attributing of fault and censure to those deemed to not acting responsibly) may result when envisioned reality (entitlement to respectful treatment) is challenged by the "facts" of provision (treatment denied or poorly delivered). These "facts" are often seen as discriminatory or anomalous and can be rationally explained (away). Those seen as responsible for 
disrupting our envisioned reality are blamed for any perceived suffering and injustice, especially when all clients must be treated equitably. In this way, someone or thing can be blamed for any problem, this being something of which practitioners must be aware. For the patient, the provider's actions or inactions have a personal impact, worsened by the provider appearing to be actively playing a positive role (Keaveney, 2006). The provider is seen as being in charge, with control over the patient's treatment and hence blame-worthy if there are harmful consequences with potential impact on trust (Alicke, 2008; Lagnado \& Channon, 2008). The provider is thus the "cause" despite their being part of a specific culture and health care system and may lose the trust of their patients. These responsibilities are socially conferred, pointing to the inferences drawn about others (Morris, Menon, \& Ames, 2001). These inferences in turn permit a spreading of blame (Tetlock, Self, \& Singh, 2010). This has been well-expressed by Lau (2009) in the context of the United States. Yet several identified elements resonate with our case. In South Africa, there has been a rights revolution, channelled by the dismantling of apartheid and the passing of the new Constitution. The country has become neo-liberalist with a reduction in public provision and a demand for individual reliance (Bond, 2013). The media plays a role in, largely, denigrating the health care system. Furthermore there is significant attention paid to the accountability of providers, (especially at the treatment level) who have been charged with a duty to care (Rowe \& Moodley, 2013).

But this duty to care is complex not only in terms of the mechanics of treatment but also with respect to the finite time and resources that providers have available to look after patients. Providers may see their behaviour as a form of implicit rationing, providing services for those they see in greatest need (Ham \& Coulter, 2001). Furthermore, there is little litigation in South Africa if treatment leads to adverse outcomes. These legal rights are barely known among patients. There is not, in most cases, an efficient system for reporting error and follow-up. Elsewhere, many providers do not report such problems or have the means to report (Perloff et al., 2006). In industrializing societies, providers may also act in an inequitable way, providing different care to different patients as dissimilar outcomes are expected (Kaler \& Watkins, 2001). Some providers (e.g. nurses) may need to feel respected because of their inferior status vis-a-vis other providers and their past more highly regarded circumstances. Most providers provide at least adequate and reasonable service to most patients. And many of patients express satisfaction with treatment. Yet if something goes wrong and they are held responsible for a health issue or treatment mistake, they may seek to avoid blame. In this case, blame is directed at patients who, it is claimed, do not follow instructions, arrive at the right times or take their treatments in the prescribed ways. They may also blame other individuals for not doing their jobs well or the system itself in not providing sufficient resources to treat all patients well. Blame does not disappear. It is transferred.

In such situations, blame attribution describes the process of making sense for both patients and providers of why events have occurred in the ways that they have (Witt, 1991). So when faced with uncertainty, people have a tendency to explain the cause of these events in an effort to control or adapt to their environment. These explanations motivate their subsequent behaviour (Heider, 1958). With successful outcomes, these beliefs, shaped by societal context and history as well as provider-patient expectations, can lead to trust being developed and maintained. That depends on institutional history and capacity as well as individual characteristics (Gilson, 2006). If not, blame and distrust (doubt or suspicion that any confidence in another person or agency is misplaced) co-mingle and are difficult to dislodge once formed (Hatzakis, 2009).

How are blame and distrust manifested? Certainly for patients, they are manifested in suspicion. Distrust, a lack of confidence in providers, leads to the belief that providers may harm, or not care about, one's welfare. A key dimension of health reform must be an explicit recognition of these suspicions. Conversely, many providers in South Africa treat patients with suspicion as they may default from care. Suspicion is one of the central cognitive components of distrust (Deutsch, 1958). Fein and Hilton (1994) argued that suspicion can be triggered by situations where perceivers have forewarnings that another might be insincere or untrustworthy, in which their expectations have been violated, and when they recognize situational cues or possess contextual information that suggests another might have ulterior motives. Those who are distrustful and suspicious are not however irrational (Kramer, 1999). Suspicion then is a state of uneasiness and uncertainty that things are not right or as they should be. So individuals act as intuitive scientists, attempting to draw reasonable inferences about others' trustworthiness and willingness to treat others fairly. And as Burkitt (2010) notes, those who feel they were let down by others on many occasions may approach all future relationships with suspicion, fuelled by distrust. The others (the same or different providers) in those future relationships may wonder why the individual is so guarded when they feel to have approached them with openness and acceptance (Burkitt, 2010).

Such responses_-combined with the sheer number of patients and limited opportunities for establishing rela- 
tionships-may often lead providers to see the patient, not as s/he appears to be but to treat them as a social category, a failure to recognize patient rights. Such categorization may heighten distrust and suspicion between individuals from different groups. The provider can view the patient as an "outsider" with little knowledge of their honesty, reliability, or, and trustworthiness. The mere fact of categorization and perceived differentiation may create presumptive distrust with providers being suspicious of some patients' "worthiness" to receive appropriate care. This may result in a spiral of increasing suspicion as patients may reversely distrust the organizations themselves. But with limited resources, patients have little choice in where they go for services. Their unmet or violated expectations lead to a further diminution of trust, a growing belief of the denial of entitlements, and an increase in blame attribution.

In this paper, therefore, we explore the ideas of blame and trust seen through a lens of suspicion that other individuals or agencies in the interactions are not acting as they should, making in our view re-engineering of care problematic. We provide examples of these ideas in the experiences of both patients and providers, noting that both groups exist in a rational, hierarchically organised society yet entrenched equality of treatment in a democracy. Before this, however, we provide background on the research setting and the employed methods.

\section{Methods}

This research is part of a five-year research study that included both quantitative and qualitative data collection strategies in several provinces of South Africa (Cleary et al., 2012; Fried, Harris, \& Eyles, 2012). This paper draws on the qualitative data, using in-depth interviews with 45 patients (CEOC_-16 patients; TB and ART-29 patients accessing tuberculosis (TB) treatment and antiretroviral (ARV) therapy) and 63 providers from twelve health facilities in three health sub-districts in South Africa-two urban (Cities of Cape Town (Western Cape) and Johannesburg (Gauteng)) and one rural (Bushbuckridge, Mpumalanga). These facilities were selected from a larger number of health care institutions with the aim to include different facility sizes, management styles as well as geographical and community characteristics. We consider access to three tracer treatments-TB, Antiretroviral Therapy (ART) and maternal deliveries-because they deal with complex, conditions that require ongoing or sustained engagement with the health system.

The data were collected between June 2009 and July 2010. Ethical clearance was granted by the Universities of Cape Town and Witwatersrand, and the relevant South African Provincial Health Research Committees. Study permission was also received from local government and district managers, as well as heads of the health facilities involved. Informed, written consent was obtained from all individuals interviewed. All interviews were anonymized and stored on a secure server available only to the research team. Pseudonyms were assigned to people and facilities to protect confidentiality.

For patients, we used an interview guide to encourage the telling of illness/pregnancy trajectories and treatment/delivery experiences within the context of everyday life: relationships, support networks, employment, education, and political transition. Appendix 1 is illustrative and the types of questions we asked and the purposes behind the questions. We were particularly interested in the challenges faced by people accessing TB, ART and maternal delivery services successfully, that is, those who were adherent to treatment or delivered in an appropriate facility and unsuccessfully, meaning treatment interrupted or babies born before arrival (BBA) at a facility. We therefore purposively sampled and recruited participants through facilities, community health workers, and local HIV/AIDS support groups, to reflect a diversity of access experiences. For TB/HIV, fourteen men and fifteen women were interviewed, of which half were "successful" users (with no self-reported missed collection or taking of treatment). Mean age of patient participants was 37, with the youngest aged 23 years, the oldest 64. We interviewed nine patients that were HIV-positive, twelve that had TB and an additional eight patients with both known TB and HIV-positive status. For CEOC, 16 women were interviewed, half of whom delivered in clinics or hospitals, and half at home or en route to a facility (born before arrival). Three quarters of these births were live but four of the women lost their babies during birth.

Patients were interviewed in their home languages by trained fieldworkers, at/outside health facilities, in their homes, or other "sites of engagement" (for example, a coffee shop in a shopping mall), where people felt comfortable to talk. Interviews were audio-recorded and lasted between 45 minutes to 1.5 hours of "recorded time” although there were often delays and interruptions — small stories of daily life — that prolonged each engagement. These provided important insights that were discussed in weekly team debriefings. Weekly meetings were held with the field workers to assess the operation of the project as well as the translation of the interviews into Eng- 
lish. Transcripts then underwent a first analysis by several team members to prepare a follow-up interview aimed to gain an impression of treatment progress and to clarify patients' narratives. However, given their complex life circumstances, not all patients could be traced successfully. After the transcription of patient interviews, the co-authors analyzed and coded all interviews using Atlas.TI or NVivo. To ensure rigor, we shared and evaluated the codes throughout, ensuring that we achieved good congruence. In selecting these narratives, we have tried to give voice to as many participants as possible. We recognize the constraints of second-language translation and, for clarity reasons, made minor stylistic and grammatical changes.

Sixty three providers (20 TB services, 21 ART and 22 CEOC) were interviewed about their career paths and understandings of patients and their lives. Additionally, one focus group took place with twelve community health workers in Bushbuckridge, covering similar issues. Audio-recorded interviews were conducted, translated and transcribed by researchers or fieldworkers. Weekly meetings were held to assess the operation of the project. Participants were identified through facility observations and were purposively selected to reflect a range of age groups, levels of seniority, and length of service. Interviews took place in health facilities (the working environment) for approximately an hour, although this varied according to provider availability. As with patients, delays and interruptions extended our interview time beyond the transcribed product, richly illustrating the daily context of health care provision. The co-authors analyzed and coded all interviews using Atlas.TI or NVivo. To ensure rigor, similar procedures as with patients were adopted.

\section{Narrative Analysis}

A narrative framework was adopted as this approach is well suited to understanding experiences of a disease. Common in the social sciences and humanities, narratives are being increasingly used in health research. This approach involves the understanding of personal stories, always conceived and told from a distinctive personal and cultural setting (Bury, 2001; Charmaz, 2004). Bury (2001) argues that narratives themselves can normalise life, provide a sense of worth or be used to obtain resources. They also express the providers' views of their worlds.

The analytical task of narrative research is therefore to convert stories into narratives through actively listening to, and interpreting, textual voices (Scollion, 1995). While interpretation starts within each story, it is not devoid of context but rather strives to make sense of personal experience in relation to cultural discourses (Fairclough, 1992). Stories can show the contradictory and shifting nature of hegemonic discourses, which we tend to take for granted. Stories are thus interpreted in situ and are often compared to similarly-located stories to gain a richer understanding of the situation, as well as the identities generated in specific contexts. We interpreted these stories by closely reading and listening to, then comparing, different voices in this context of provider-patient interaction. Our resultant narratives are one interpretation. However, rigorous a narrative research is not devoid of methodological rigour or “trustworthiness”. It can indeed possess validity (Onwuegbuzie \& Leech, 2007). Interpretation needs to be grounded in the texts analysed and tested against other explanations and a-typical cases, to show its feasibility. In our analysis, we embarked on an iterative process of interpretation by collectively sharing and debating our understanding of the stories in light of the theme of how patients and providers regard one another and how this affects interactions and treatment relations.

\section{Results}

\subsection{Suspicion among Patients}

In the following narratives, we set out those occasions in which patients regard providers and the health care system with mistrust and suspicion. These may direct views and experiences and potentially to providers being blamed for appearing to provide inadequate care. These include failure to see a doctor when expecting to see one; not being informed of adverse outcomes; being treated disrespectfully by providers; among TB patients the suspected use of sputum by other patients and staff; not qualifying for grants or being denied access to grants by providers; and other patients queue jumping.

\subsubsection{No Respect}

The most common occurrences were experiences of being treated with little respect or as ignorant of care needs or system operation, usually irrespective of how others were treated. No respect is often viewed suspiciously as 
it means patients are often treated as objects and responsible for their own illnesses and others are perceived as enjoying better treatment and share of resources. Such experiences may themselves lead to defaulting from treatment.

"I stopped taking my treatment because the nurse that I was supposed to get treatment from was not polite to me. She talked to me in an impolite manner in front of her staff. She told me where to get off because I was late on that day and she complained about how they assemble their card system so because I am late she said I should come back on Wednesday but I thought clinics operate until 4 pm [the designated closure time]...” (PAЗa)

In such a case, the patient blames some of their problems on the unhelpfulness of the staff, noting that their actions had led staff to comment that the patients had not fulfilled their "duties" as a client so they were no longer responsible for their care. Furthermore, overall impoliteness, manifested as perceived rudeness to sick people can have the effect of increasing mistrust and suspicion, often leading to tension in the waiting area. With staff waiting to blame patients for doing things incorrectly, i.e. not fitting in this staff notions of correct behaviour.

The provider may lose patience with the patient, ignoring their life circumstances, i.e. working and disrespect over use of patient's time. This disrespect of patient time leads to the suspicion that they could wait all day and it would not matter to provider:

Patient 18a talks of their TB tablets:

"Like today if I feel it is a distance and at first they told me she will be there at three o clock and I went there three o clock and they told me no after six and I came back to the clinic because I did not get my pills I had to wait for strength to come here and I told them here and they said they will talk to her and I got an answer that she will be there at seven o clock in the evening because she is working. I can't make it, it is dark that time and it is far and there is no way I can go there."

Patient 1a and, Patient 41b talk about the lack of respect and dereliction of duty:

"The reason that made them to keep quiet is that some of the nurses are very hard, when you talk to them they just ignore... patients. ... It is like when you find that the complainant is bedridden and tries to call the nurse next to s/he and the nurse just leave without attending to that patient..." (PA41b)

This lack of attention to duty can lead to patient being seen as a non-person with few abilities to treat themselves:

"No MOU that was so offish with the patients ... they are moody and I could see, if they see you are single then they treat you as a child... I went in the night and the security said I must wait and the sister came to call me and she said I must get undressed and go to the loo and she gave me a urine container and I went to urinate and she told me to lie on the bed but I must remove my panties and when I was lying with my legs opened to her because I didn't know how to lie she was yelling at me and told me how can I lie in that position because she was not going to look there and she was laughing with the other nurse...” (PA15)

So much connected with patients seemed too much trouble. When staff ignore pain, laugh, and chastise their behaviours, it is not surprising some patients lack trust in the care provided, feel unwanted and present a bother, leading to a suspicion of not caring, even undermining the ways in which patients see themselves and their identities (PA27).

\subsubsection{Poor Treatment}

For some patients, this lack of respect means that staff are not trusted and their skills and the treatment regime are in doubt. Suspicion is deepened and some staff are blamed for this poor state of affairs. Patient PA8 reports that lack of trust can also stop patients discussing side effects and treatment complications, reducing the chance of addressing underlying issues or of adjusting treatment schemes to ensure success.

There is in some cases little continuity in the staff which treats patients. Suspicions are elevated by this for both nurses and doctors who may seem distant from patients: here again, contributes to eroding patient trust. Doctors are perceived as incompetent with poor interpersonal skills, with PA34 reporting the prescribing of treatments without any examination.

\subsubsection{Poor Grant Intermediaries}

These suspicions about competence are exacerbated as doctors and nurses are not only important for medical treatment but also for timely access to monetary resources such as grants. In some ways, staff can be blamed for 
patients having to live in poverty with their illnesses:

"Nobody at the clinic told you that the TB patients can get a grant?" (Interviewer)

"No" (PA17b)

“And you never asked?” (Interviewer)

"No I did not know about the grant and if I can get it or not." (PA17b)

This cavalier approach to grants leads to a deeper suspicion that medical staff do not care for all patient needs or deny permanent grants over temporary ones (PA22).

These suspicions of not caring spill over into thoughts of corruption:

"One other thing you must not say this (with a low voice and sort of whispering) they were giving me a lot of tablets here and put the date away/far. I think they did not want me to get this grant because they were putting my dates away and gave a lot of tablets and said I must not tell. I must drink them at home when they were finished then I must come and get another one... So maybe that is why I did not get grant is because they were doing that. Again someone told me that here they can take someone's sputum and give it to someone else and then that person get the grant they split that money, but I don't know whether it is the truth but I heard someone saying that." (PA23b)

\subsubsection{Seriousness about Treatment: Asymmetry of Relationships}

But more common than perceived corruption is a feeling of little concern for patients, demonstrated in the regimentation of treatment. This may reinforce the mistrust of patients with staff. So after arrival,

"I usually put it on the table there where the nurse is sitting and then they call me then they say I must take my pills and after that they sign if they want to then they will give me tomorrow's pills I just told them straight I can't come tomorrow I can't make it I can't walk every day so far and the same distance back I can't” (PA18a)

"And what did the nurses say?” (Interviewer)

"They said I must make a way to come to the clinic, I must just come there is nothing they can say I must just come if I want to be cured..." (PA18a)

But this regimentation is limited to hours that suit the providers or clinics that have been demarcated for specific populations at specific times, adding not only to poor treatment but eroding trust and increasing the suspicion that the health professionals are simply filling time in ways that suits them best (PA24).

Patients appear to be treated like objects with little feeling, exacerbated likely the difficulty of dealing with death. After a very difficult labour,

"They did not give me the baby. I was exhausted and I kept on telling her give me the baby!, and I even asked if they have given him the baby drops because they were supposed to give him Neviropine for seven days and I kept on pushing and insisting to see the baby well they said the baby is fine and I should not worry at I think it was eleven when baby was born and after a couple of minutes I wanted to get off the bed I did not realizes that I could not walk and I saw a nurse coming with a doctor and for some reason I felt that something was wrong but I did not want to dwell on it. ... the other nurse asked me how was the baby when it came out, was the baby crying? And I said no he wasn't crying and then they kept quiet and something came over me I could feel there was something wrong but I didn't want to assume you know, and the doctor said we tried to wake him up but we could not make it and I was like almost in disbelief and she took the file and showed me the file and I realized that it wasn't my file so for a moment I thought they made a mistake, and the doctor asked the nurse what is the tag on the baby's hand written and nurse said baby Mpofu and I was like it can't be my baby. ... I was angry and I won't say that I was not. So on Friday morning they came to fetch me ... to check me and that I should get counseling. And I did not want to be there and my mother said there is no need for me to stay and that they wanted to prepare a funeral service for the baby." (PA27)

This final narrative encapsulates many of the behaviours that lead to mistrust and suspicion of poor care, inadequate communication, a remoteness bred by a self-serving approach to their jobs. If this is the context of the care received in these cases, then it is not surprising that providers become blamed for both the poor care and the context of treatment provision itself.

\subsection{Suspicion among Providers}

Providers, on the other hand, are suspicious of patient behaviour and their failure to live up to expectations or pursue recommended treatment, such as using muti and traditional medicines; patients thinking appointment 
system does not matter; expecting treatment to be available on demand; not respecting skills of staff; and being caught between the ignorance of patients and that of senior managers, with both groups being blamed for poor practice with the suspicion that patients are abusing the system and a level of mistrust with the ways in which senior managers act.

\subsubsection{Patients Require Guidance and Are Ignorant}

Patients are therefore often regarded by providers as ignorant or like children, not fully understanding the seriousness of their condition and unwilling to follow medical advice. There is a suspicion that they do not really want to get well and may want to abuse the system to obtain grants:

“What I've discovered ... is, if our patients come to the facility they are very sick, very sick, like for example we had 1 with a CD4 count of 2 and then Ashleena was mentioning to me there 2 days ago there was a gentlemen with a CD4 count of zero, the patients are very sick, so they come here with the idea today I will get my $A R V$ 's and it's not like that because we know ART to be enrolled on the ART program is a process so then because they don't get their ART's the very same day they come to the clinic, some of them just simply go to the Eastern Cape. They seek traditional help." (PR50)

PR4 is more blunt:

"So our patients, they seem to be very, very ignorant. Even in the ward, when you ask her: 'now that you are staying next to the clinic, you can just walk by, you just walk to the clinic, you don't even need money for the taxi or what, why didn't you go to the clinic?' She will just tell you: 'I was not aware how far pregnant I am'. You have been aware that you are not working both but you've decided not to go to family planning. That's a bit on the stupid side because if your boyfriend, my girlfriend's not working, really, I should think for myself that 'why must I fall pregnant?'”

\subsubsection{Overstretched but Caring Staff}

Providers see themselves as run ragged by demanding and abusive patients, placing an undue and undeserved burden on staff that are already faced with limited human and other resources (PR50, PR4). Staff remain professional and calm, trying to ensure equity among patients seeing those with the greatest need first:

"Eh they demand sometimes they are some of them are frustrated because of their condition and they will react sometimes they will even be very rude and so on yes but I came to realize these are patients who are having problems who are in a certain condition and I have to be very sensitive and understanding." (PR26)

\subsubsection{Demanding, Disorganised, Dishonest, and Defaulting Patients}

The ignorance of patients may be reinforced by their perceived dishonesty and failure to recognise the importance of treatment. Patients are often disorganised and show little respect for staff and their activities and spaces. They become suspicious that patients may not care about getting well. Patients are not only seen as demanding but dishonest as well:

"Ya they do come they will say I left my bag in the taxi or they got stolen or there were floods in the shack. They will come up with all sorts of stories of which you never know whether they were true or not. At the end of the day you have to supply treatment to the patient. If I tell you that I lost the medication, I lost the medication there is nothing that you can do. You have to dispense it to the patient but the things is we told them, that what they are being taught at the adherence classes they tell them you know what if you lose your tablets you go to the police station So then they have to come in with an affidavit but if you are coming to me and you are saying I lost my medication I will ask you didn't they teach you that you have to make an affidavit? If you say no I will say well, I will give you medication for tonight; tomorrow you go to the police station you make an affidavit and then you come with the affidavit and then you come with that you see." (PR25)

This paternalistic regime is maintained to limit the numbers of defaulting patients. Yet despite knowledge of the difficult life circumstances of patients, providers still blame them for such defaulting

"And, our TB patients when they start to feel better they will give you trouble, they want to default. The next thing you find that they are visiting [out of town] and you can't find them especially after two months now you start to have problems and they would say, 'I feel better now'. And say that, 'at the hospital they said my TB is cured' and they [the hospital] will never say that and knowing that you were looking for her maybe she went to visit in Mafikeng. And now you find that she is infecting other people and that is why I try to encourage them and say it is better if you can just stay for full six months for the period of this treatment..." (PR22) 
Patients are also disorganized, presenting at the wrong time and place, leading to uncaring behaviour on the part of some staff, including administrative clerks who act as gatekeepers to the system. Patients are expected to know the customary practices of the clinic:

"Like to say; you were saying that Fridays you keep them for stats and administrative tasks. So if patients come on Fridays and you know that Friday is a day specifically for admin work how would you juggle that?" (Interviewer)

"We do dispense to the patients... in the morning you find that I would do those patients that were there and then I will start doing my admin work. So if we had already started doing the stock counts and everything we will give them the few patients that you find, maybe the patient walks in at about 11 o'clock. Because the clinic closes at 1 o'clock. They walk in at about they have got this tendency of walking in at 12 o'clock half past twelve you see of which we closing at 1 o'clock and then it's a half day and they know that. In that case we will give you few for a week. Let's say you don't have tablet for the weekend you see we will give you a few for five days, because all of those patients are defaulters because we don't book patients on Fridays you see. We don't we don't book any patients on Fridays." (PR27)

"Ok and all the patients know this?" (Interviewer)

"The patients yes they know. They know that the clinic close early on Fridays. It closes one o'clock and the other days its seven till four.” (PR27)

\subsubsection{Diligent Care}

Yet staff believe, despite these "ungrateful" patients that they do their jobs diligently with too high a workload. PR4, a nurse from Bara, speaks of helping new or trainee doctors:

"They rely on us, they will ask us anything. If it's a paediatrician, she comes in, she has been told that 'go there, get the sister-in-charge of the ward, when you are checking on your babies, where you are not sure, go to her, she'll tell you'. You tell them. We admit mothers, we admit babies. Our Labour Ward is so hectic. ... There's too much responsibility. There is no staff. There is no, you know... nobody motivates you. Nobody comes to you to say at least: 'thank you guys, you are trying.' So those are some of the things that why nurses are leaving. Especially Bara. Nurses are leaving Bara in a huge number... The cream is leaving the country. It's not always about the money. It's about the conditions. As the doctors were striking, they say the conditions are poor. The conditions are not conducive..."

Providers thus see their competencies threatened by some of the practices in health care in South Africa today. They often see themselves as not being respected for their expertise and blame overwork for not being able to provide good, caring practice all the time. They blame ignorant patients for making too many demands about which they are very suspicious of the worth of their claims. Thus patients concerns are often delegitimized and their motives mistrusted. Ignorance and lack of medical understanding are blamed (Contamin, 2012). Blaming patients for not knowing what providers are doing for them despite all the pressures they themselves face.

\section{Discussion}

Mistrust, blame and suspicion are responses to appearing to be treated poorly and inequitably in a system where (normative) expectation is of equitable treatment, especially in the aspirational environment of post-apartheid health care. The onset of democracy brought entrenched constitutional rights and these, despite significant progress, are deemed in short supply. The corporatist nature of South African society with its important, entrenched professions and ways of practice means providers may not be able to provide services in the ways in which patients expect (although little is known of patient expectations). If expectations are not met, mistrust about the ability of a service to provide may arise. The naive trust which patients may have in providers is challenged by limited and uncaring service. (Indeed this naïve trust may be an acquiescence in the face of little or no choice in treatment.) Patients may regard some providers as being unable to carry out their jobs. The growing importance of patients' rights and transparency and accountability principles in health care (certainly features of a neo-liberal stance) may lead to judging providers on the basis of conventional roles models of providers (expert, caring, available). Yet providers do not see all patients treating them with respect to these expectations. Patients are no longer always pliant: they lack trust in the services and become suspicious of interactions with providers and with how the health system itself responds to their perceived needs. But providers are under pressure too. They must provide care, meet targets and spend resources effectively. If they find it difficult to achieve this 
then they blame the ignorant patient and become suspicious of what the health system hierarchy demands of them. Some suspect they are being de-skilled, poorly regarded and in between the demands of the liberated patient and the constraining system. This is part of the health service microcosm that has arisen in the tensions between the post-apartheid acquistional democratic and past authoritarian past states. But a way forward may be not to develop trusting relations but to deal with mistrust. As Ivan Krastev (2013) says, "transparency is not about restoring trust in institutions. Transparency is the politics of managing mistrust.” This may be difficult if service delivery concerns lead to the transfer of blame. This heightens mistrust, leading to suspicions and to transparency being problematic to operationalise.

Yet as part of transparency, it is likely that cooperative policy- and decision-making require multi-stakeholder governance with citizen involvement to increase democratic accountability and respectful behaviour for this constitutional and life-affirming right-access to available, affordable and acceptable health care. But part of this governance structure must involve detailed interrogations of the needs, wants and motivations of all stakeholders. What patient expectations are realistic? What incentives can engage providers to alter practice? These matters are very much part of the health care transformation now occurring in South Africa (McIntyre \& Ataguba, 2012) in which quality of care and respectful relationship are as important as increased availability of medical resources. In fact, we argue that while some practitioners know of these issues of trust and suspicion many policy-makers appear not to take these matters on board as they create policy initiatives and transform management. In its National Development Plan, South Africa recognizes the need to build a capable state through creating better management practices and strong manager-administrator linkages (National Planning Commission, 2011). Yet the plan reads as a top-down policy. Although it recognizes the need to transform service delivery for citizens, they go unaddressed in building this state. Such co-operation is needed as our study shows to overcome suspicion and distrust. If this is not the case, it is likely that suspicion and mistrust will grow.

\section{Conclusion}

In this paper, a qualitative approach has been employed to permit the narratives of patients and providers in ART, TB and maternal services to reveal some of the tensions present in the delivery of health care in the public sector in South Africa. The country's unique past of the apartheid state as well as its transformation to a democratic state has shaped these interactions between patients and providers. Modes of professional training remain steeped in the past while the last 20 years have seen a growing sense of entitlement among poor, black citizens. These conditions and perceptions point to the importance of blame, mistrust and suspicion in provider-patient interactions. Patients are suspicious of providers because of their disrespectful, uncaring treatment while providers see patients as often ignorant and not caring if they get better or not. The mistrust and apportioning of blame seem to be enhanced by these suspicions and changing these relationships and perceptions is an uphill task.

\section{Acknowledgements}

This research was funded by the Teasdale-Corti Fund of the International Development Research Centre of Canada. The authors also wish to thank their colleagues in the Researching Equity and Access to Healthcare in South Africa for their assistance and advice in undertaking this research. We acknowledge the time and patience given to us by our respondents. John Eyles' research program is supported in part by the Department of Science and Technology through the Research Chair Program of the National Research Foundation.

\section{References}

Alicke, M. D. (2008). Blaming Badly. Journal of Cognition and Culture, 8, 179-186. http://dx.doi.org/10.1163/156770908X289279

Bond, P. (2013). Debt, Uneven Development and Capitalist Crisis in South Africa: From Moody’s Macroeconomic Monitoring to Marikana Microfinance Mashonisas. Third World Quarterly, 34, 569-592. http://dx.doi.org/10.1080/01436597.2013.786283

Burkitt, I. (2010). Fragments of Unconscious Experience: Towards a Dialogical, Relational, and Sociological Analysis. Theory and Psychology, 20, 322-341. http://dx.doi.org/10.1177/0959354310362827

Bury, M. (2001). Illness Narratives: Fact or Fiction? Sociology of Health \& Illness, 23, 263-285. http://dx.doi.org/10.1111/1467-9566.00252 
Charmaz, K. (2004). Premises, Principles, and Practices in Qualitative Research: Revisiting the Foundations. Qualitative Health Research, 14, 976-993. http://dx.doi.org/10.1177/1049732304266795

Cleary, S., Birch, S., Moshabela, M., \& Schneider, H. (2012). Unequal Access to ART: Exploratory Results from Rural and Urban Case Studies of ART Use. Sexually Transmitted Infections, 88, 141-146.

http://dx.doi.org/10.1136/sextrans-2011-050136

Contamin, J. G. (2012). You, You Are in the Emotion. Me, I Am in the Management. The Delegitimization Frames of Citizen Protests. The Case of a French Bill about Immigration. Presented at IPSA 20th Congress, Madrid 2012.

http://paperroom.ipsa.org/papers/paper_12183.pdf

Coovadia, H., Jewkes, R., Barron, P., Sanders, D., \& McIntyre, D. (2009). The Health and Health System of South Africa: Historical Roots of Current Public Health Challenges. The Lancet, 374, 817-834. http://dx.doi.org/10.1016/S0140-6736(09)60951-X

Desai, A., \& Habib, A. (1997). Labour Relations in Transition: The Rise of Corporatism in South Africa's Automobile Industry. The Journal of Modern African Studies, 35, 495-518. http://dx.doi.org/10.1017/S0022278X9700253X

Deutsch, M. (1958). Trust and Suspicion. Journal of Conflict Resolution, 2, 265-279. http://dx.doi.org/10.1177/002200275800200401

Fein, S., \& Hilton, J. (1994). Judging Others in the Shadow of Suspicion. Motivation and Emotion, 18, 167-198. http://dx.doi.org/10.1007/BF02249398

Fairclough, N. (1992). Discourse and Text: Linguistic and Intertextual Analysis within Discourse Analysis. Discourse and Society, 3, 193-217. http://dx.doi.org/10.1177/0957926592003002004

Fried, J., Harris, B., \& Eyles, J. (2012). Hopes Interrupted: Accessing and Experiences of Antiretroviral Therapy in South Africa. Sexually Transmitted Infections, 88, 147-151. http://dx.doi.org/10.1136/sextrans-2011-050140

Gilson, L. (2006). Trust in Health Care: Theoretical Perspectives and Research Needs. Journal of Health Organization and Management, 20, 359-375. http://dx.doi.org/10.1108/14777260610701768

Gilson, L., Pamer, N., \& Schneider, H. (2005). Trust and Health Worker Performance: Exploring a Conceptual Framework Using South African Evidence. Social Science \& Medicine, 61, 1418-1429. http://dx.doi.org/10.1016/j.socscimed.2004.11.062

Ham, C., \& Coulter, A. (2001). Explicit and Implicit Rationing: Taking Responsibility and Avoiding Blame for Health Care Choices. Journal of Health Services Research \& Policy, 6, 163-169. http://dx.doi.org/10.1258/1355819011927422

Hatzakis, T. (2009). Towards a Framework of Trust Attribution Styles. British Journal of Management, 20, 448-460. http://dx.doi.org/10.1111/j.1467-8551.2008.00596.x

Heider, F. (1958) The Psychology of Interpersonal Relations. New York: John Wiley \& Sons. http://dx.doi.org/10.1037/10628-000

Kaler, A., \& Watkins, S. C. (2001). Disobedient Distributors: Street-Level Bureaucrats and Would-Be Patrons in Community-Based Family Planning Programs in Rural Kenya. Studies in Family Planning, 32, 254-269. http://dx.doi.org/10.1111/j.1728-4465.2001.00254.x

Keaveney, S. (2006). The Blame Game: An Attribution Theory Approach to Marketer-Engineer Conflict in High-Technology Companies. Industrial Marketing Management, 37, 653-663. http://dx.doi.org/10.1016/j.indmarman.2008.04.013

Kramer, R. (1999). Trust and Distrust in Organizations: Emerging Perspectives, Enduring Questions. Annual Review of Psychology, 50, 569-598. http://dx.doi.org/10.1146/annurev.psych.50.1.569

Krastev, I. (2013). The Transparency Delusion. Eurozine. http://www.eurozine.com/pdf/2013-02-01-krastev-en.pdf

Lagnado, D. A., \& Channon, S. (2008). Judgments of Cause and Blame: The Effects of Intentionality and Foreseeability. Cognition, 108, 754-770. http://dx.doi.org/10.1016/j.cognition.2008.06.009

Lau, R. W. K. (2009). The Contemporary Culture of Blame and the Fetishization of the Modernist Mentality. Current Sociology, 57, 661-683. http://dx.doi.org/10.1177/0011392109337651

Louwrens, P. (1996). Relations between State, Capital and Labour in South Africa: Towards Corporatism? Journal of Theoretical Politics, 8, 255-281. http://dx.doi.org/10.1177/0951692896008002008

McIntyre, D., \& Ataguba, J. E. (2012). Modelling the Affordability and Distributional Implications of Future Health Care Financing Options in South Africa. Health Policy and Planning, 27, i101-i112. http://dx.doi.org/10.1093/heapol/czs003

Morris, M. W., Menon, T., \& Ames, D. R. (2001) Culturally Conferred Conceptions of Agency: A Key to Social Perception of Persons, Groups, and Other Actors. Personality and Social Psychology Review, 5, 169-182. http://dx.doi.org/10.1207/S15327957PSPR0502 7

National Planning Commission (2011). National Development Plan. Pretoria: NPC.

Ní Raghallaigh, M. (2013). The Causes of Mistrust amongst Asylum Seekers and Refugees: Insights from Research with Unaccompanied Asylum-Seeking Minors Living in the Republic of Ireland. Journal of Refugee Studies. 
Olsen, J. P. (2009). Democratic Government, Institutional Autonomy, and the Dynamics of Change. West European Politics, 32, 439-465. http://dx.doi.org/10.1080/01402380902779048

Onwuegbuzie, A. J., \& Leech, N. L. (2007). Validity and Qualitative Research: An Oxymoron? Quality \& Quantity, 41, 233249. http://dx.doi.org/10.1007/s11135-006-9000-3

Perloff, R. M., Bonder, B., Ray, G. B., Berlin Ray, E., \& Siminoff, L. A. (2006). Doctor-Patient Communication, Cultural Competence, and Minority Health: Theoretical and Empirical Perspectives. American Behavioral Scientist, 49, 835-852. http://dx.doi.org/10.1177/0002764205283804

Rowe, R., \& Calnan, M. (2006). Trust Relations in Health Care-The New Agenda. European Journal of Public Health, 16, 4-6. http://dx.doi.org/10.1093/eurpub/ckl004

Rowe, K., \& Moodley, K. (2013). Patients as Consumers of Health Care in South Africa: The Ethical and Legal Implications. BMC Medical Ethics, 14, 15. http://dx.doi.org/10.1186/1472-6939-14-15

Scollion, R. (1995). Plagiarism and Ideology: Identity in Intercultural Discourse. Language in Society, 24, 1-28. http://dx.doi.org/10.1017/S0047404500018388

Tetlock, P. E., Self, W. T., \& Singh, R. (2010). The Punitiveness Paradox: When Is External Pressure Exculpatory-And When a Signal Just to Spread Blame? Journal of Experimental Social Psychology, 46, 388-395. http://dx.doi.org/10.1016/j.jesp.2009.11.013

Witt, L. A. (1991). Negative Affect as a Moderator of Role Stressor-Commitment Relationships. Military Psychology, 3 , 151-162. http://dx.doi.org/10.1207/s15327876mp0303 2 